\title{
PERFORMANCE OF Eu-DOPED OXIDE FILMS FOR ADVANCED MATERIALS ENGINEERING AND ENERGY CONVERSION: ARGUMENTS FOR THE LATTICE COMPATIBILITY THEORY (LCT)
}

\section{AYŞE YUMAK ${ }^{1}$, KAREM BOUBAKER ${ }^{2}$, ANDREA COLANTONI ${ }^{3}$, PETYA PETKOVA $^{4}$, DANILO MONARCA ${ }^{3}$, MASSIMO CECCHINI $^{3}$ and LEONARDO LONGO ${ }^{3}$}

${ }^{1}$ Department of Physics

Faculty of Arts and Sciences

Marmara University

34722 Göztepe

Istanbul

Turkey

2Unité de Physique des Dispositifs à Semi-Conducteurs

Tunis El Manar University

Tunisia

e-mail: mmbb11112000@yahoo.fr

${ }^{3}$ Department of Agriculture Forest

Nature and Energy (DAFNE)

University of Tuscia

Italy

${ }^{4}$ Shumen University "Konstantin Preslavsky"

115 Universitetska Street

9712 Shumen

Bulgaria

Keywords and phrases: doping, nanostructures, single crystal growth, rare earth compounds, energy compound, semiconducting ternary compounds.

Received October 30, 2015 


\begin{abstract}
In this study, some arguments for the recently discussed materials-related Lattice Compatibility Theory (LCT) are presented. Fundaments are based on the recorded behaviour disparity of some rare earth doped oxides. Incorporation of $\mathrm{Eu}^{3+}$ ions during growth has been demonstrated through Urbach tailing and Faraday effect analyze, implying the possibility of loading of similar rare earth elements species into the nano-channels of ternary and quaternary materials for energy conversion.
\end{abstract}

\title{
1. Introduction
}

Oxide thin-film crystals like lithium liobate $\left(\mathrm{LiNbO}_{3}\right)$ strontiumbarium niobate $\left(\mathrm{Sr}_{x} \mathrm{Ba}_{(1-x)} \mathrm{Nb}_{2} \mathrm{O}_{6}\right)$, sillenite single crystals $\left(\mathrm{Bi}_{12} \mathrm{SiO}_{20}\right)$, and $\left(\mathrm{Bi}_{12} \mathrm{GeO}_{20}\right)$ etc. are well known photorefractive and energyconversion related materials with several applications in laser resonators and phase-conjugated spatial-time light modulators and non-linear integral optics [1-10]. These materials are very efficient photoconductors with low dark conductivity that allow a build-up of large photo-induced space-charges. Particularly, their relatively large optic and Faraday effect of sillenite oxides makes them useful for optical fiber magnetic fields sensors. It has been recorded that doping agents induced latticescale and topological disorder during crystal growth along with atomicscale dispersion in these crystals. In the particular case of rare-earth doping, it has been noted that these materials interact differently with rare-earth elements and exhibit odd behaviours despite their chemical similarities [7-10].

In this paper, new patterns of elements of these growth-related behaviours are explained and discussed in the framework of the Lattice Compatibility Theory (LCT). The paper it organized in the following way: In Section 2, we present some relevant experimental details along with main rare earth doping features. In Section 3, we present Urbach tailing and Faraday effect analysis along with LCT patterns. Section 4 is conclusion. 


\section{Experiment}

\subsection{Experimental details}

Oxide thin-film crystals have been grown using the polymeric precursor and Pechini methods [11-12] using benzoic acid, lithium benzoate, titanium tetra-isopropoxide, strontium carbonate, bismuth acetate, and barium carbonate as precursors. Complexation and $\mathrm{pH}$ adjustment were achieved by using wet ethylene glycol and the ammoniacal complex $\mathrm{NH}_{4} \mathrm{H}_{2}\left[\mathrm{NbO}\left(\mathrm{C}_{2} \mathrm{O}_{4}\right)_{3}\right] \cdot 3 \mathrm{H}_{2} \mathrm{O}$, respectively.

The Eu-doped samples have been consecutively prepared by adding $\mathrm{EuCl}_{3}$ (Europium (III) chloride salt) in a stoichiometric ratio to the asgrown crystals. The concentration of the doping agent within $\left(\mathrm{Eu}^{3+}\right)$ the obtained crystals has been estimated by using emission spectral analyses and chemical absorption with an accuracy of $4 \%$.

X-ray diffraction analysis of all prepared compounds was performed by a copper-source diffractometer (Analytical X Pert PROMPD), with the wavelength $(\lambda=1.54056 \AA)$ while optical absorption spectra were measured on double-side polished parallel crystal plates using a SPM-2 monochromator within accuracy of $\pm 2 \mathrm{~nm}$.

\subsection{Eu-doping features}

It has been recorded [13-16] that Europium doping during crystal growth enhances the radiation resistance of oxide thin-film crystals by introducing a additional slow decay fluorescence in the dominant wavelength range of red and a loss of light output. The induced fluorescence originates from the radiative transitions of ${ }^{5} \mathrm{D}_{0}$ level to

${ }^{7} \mathrm{D}_{0},{ }^{7} \mathrm{D}_{1},{ }^{7} \mathrm{D}_{2}$, and ${ }^{7} \mathrm{D}_{3}$ levels of $\mathrm{Eu}^{3+}$, which has a slow time constant (about 2.0ms) [15-16]. 


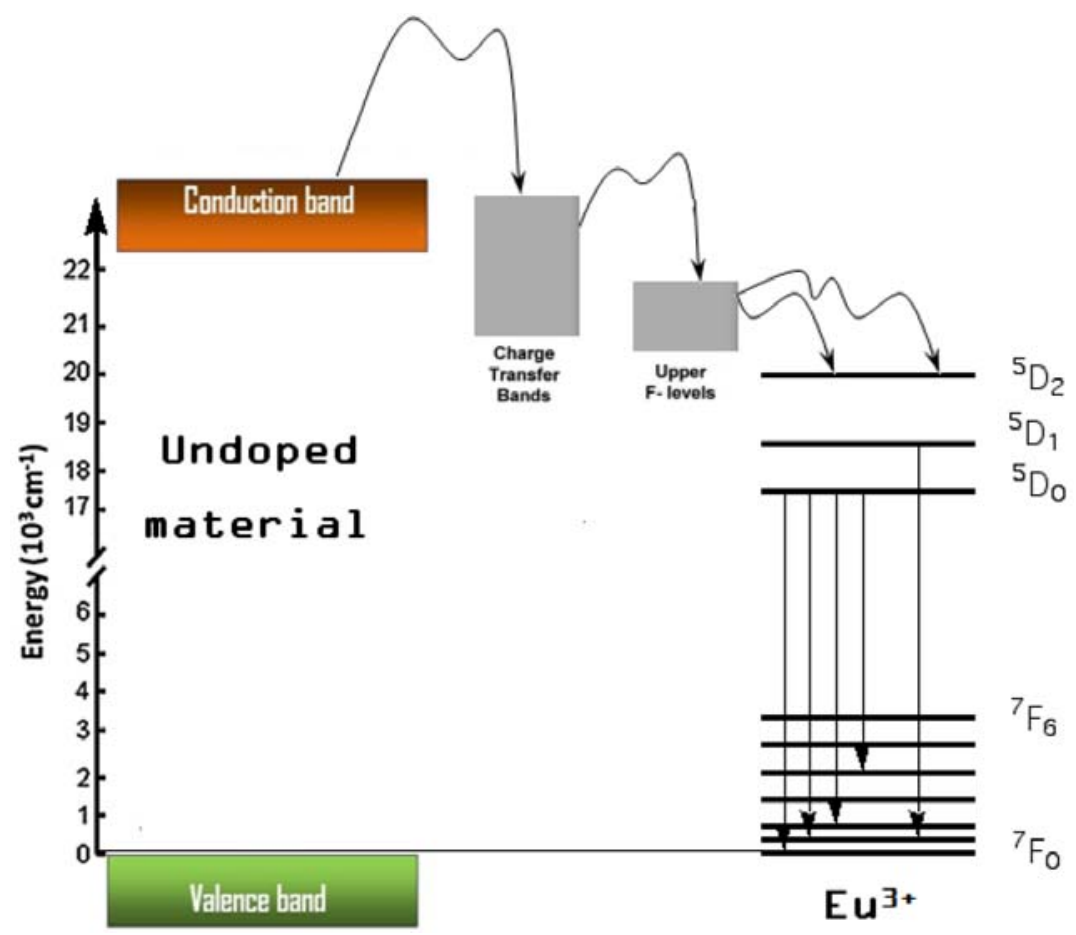

Figure 1. Combined energetic levels schemes.

Chemical properties of $\mathrm{Eu}^{3+}$ ion, which is a good representative for most rare earth elements, also enables its incorporation inside existing matrices. Hasegawa et al. [15] and Marwoto et al. [16] used Eu-element radiation rates and emission quantum yields along with combined energetic levels schemes (Figure 1) to prove that the oxides crystals incorporate $\mathrm{Eu}^{3+}$ ion as a consequence to electron possible pathways transition at either host matrix upper conduction band level or between doping agent levels (Figure 2). 


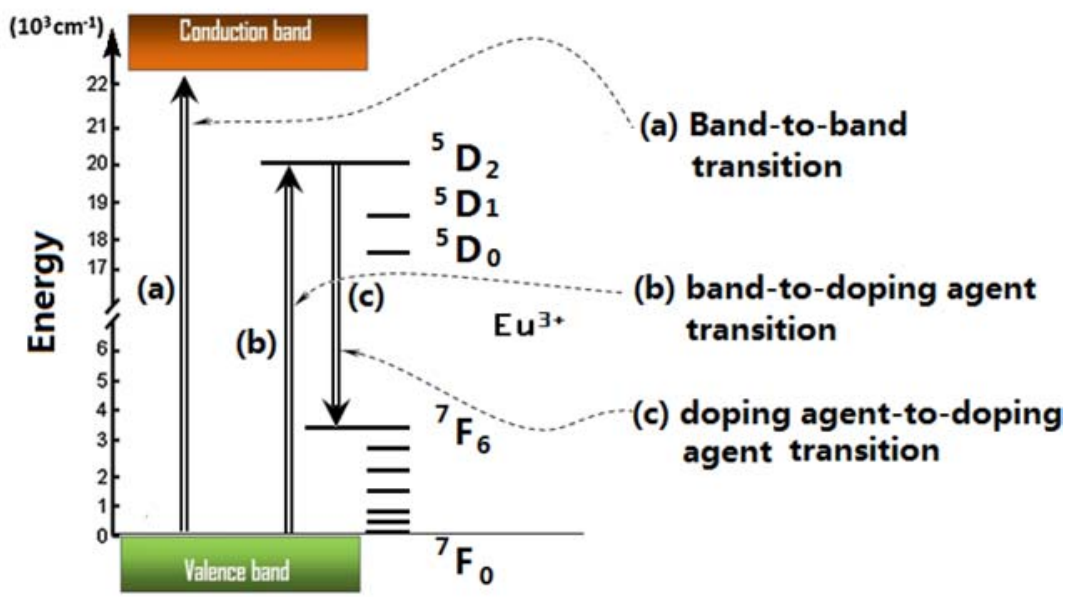

Figure 2. $\mathrm{Eu}^{3+}$ induced pathways transition at host matrix and doping agent levels.

\section{Results and Discussion}

\subsection{Eu-doping patterns terms of Urbach tailing and Faraday effect}

Urbach tailing and Faraday effect are recently implemented aggregates for the evaluation of nanostructures stability. Urbach tailing alteration following doping agent insertion in host structures is evaluated through the Urbach energy $E_{u}$ which determined, for doped and un-doped samples through the equations:

$$
\left\{\begin{array}{l}
\operatorname{Ln}(\alpha(h v))=\operatorname{Ln}\left(\alpha_{0}\right)+\frac{h v}{E_{u}} \\
E_{u}=\alpha(h v)\left(\frac{d[\alpha(h v)]}{d[h v]}\right)^{-1}=h\left[\frac{d}{d v}(\operatorname{Ln} \alpha(v))\right]^{-1},
\end{array}\right.
$$

where $\alpha(h v)$ represents, for each sample, the experimentally deduced optical absorption profile. It has been proved that Urbach energy $E_{u}$ is a measure of the inhomogeneous disorder and atomic scale dispersion inside structures as it indicates the width of the band tails of the 
localized states in presence of defects. Its analytical formulation deduced by takes into account three components: structural disorder, carrierphonon interaction, and carrier-impurity:

$$
E_{u}=\overbrace{\frac{1}{2} k_{B} U \theta_{D}}^{\text {Structural disorder }}+\overbrace{F \frac{4 \pi^{2} Z^{2} q^{4} m^{*} L_{D}^{3}}{9 \sqrt{3} \varepsilon^{2} \hbar^{2}}}^{\text {Carrier-phonon interaction }}+\overbrace{F^{\prime} \operatorname{coth}\left(\frac{F^{\prime \prime}}{2 k_{B} T}\right)}^{\text {Carrier-impurity }},
$$

with:

$k_{B}: \quad$ Boltzmann constant;

$U: \quad$ Lattice strain related with the structural disorder;

$\theta_{D}:$ Debye temperature;

$L_{D}:$ Debye length;

$m^{*}:$ Carrier effective mass;

$Z$ : Impurity charge;

$q$ : Electron charge;

$\varepsilon: \quad$ Static dielectric permittivity;

ћ: Planck's constant;

$F, F^{\prime}, F^{\prime \prime}:$ Constants.

The width of the localized states (band tail energy or Urbach energy $E_{u}$ ) has been estimated (Figure 3) from the slopes of the plots of $(L n \alpha(v))$ versus energy $h v$. 


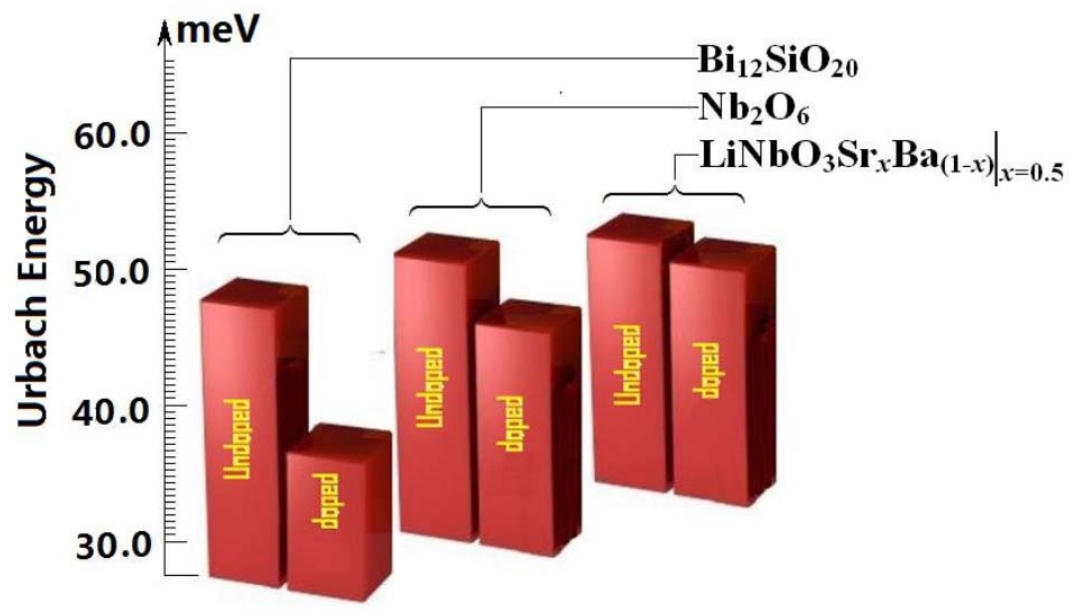

Figure 3. Urbach tailing and localized states in presence of defects.

Faraday effect (or Faraday rotation effect) is a magneto-optical phenomenon which was revealed in the beginning of the last century by Michael Faraday [17], and which consists of an interaction between light and a magnetic field inside a given medium. It causes a rotation of the plane of polarization which is linearly proportional to the component of the magnetic field in the direction of propagation. The Faraday effect is based on the notion of circular birefringence, which causes a difference of propagation speed between left and right circularly polarized waves.

Faraday effect has been evaluated, for the obtained samples, through the measurements of alterations of the Verdet coefficient $V$ within the visible spectral domain. This coefficient is deduced via the measurement of the polarisation rotating angle $\theta$, using the formula:

$$
V=\frac{1}{B l} \theta,
$$

with:

$B$ : Applied magnetic field strength (in oersteds);

$l$ : Light path length through the medium. 
Verdet coefficient $V$ changes for doped and un-doped samples have been recorded in Table 1 .

Table 1. Verdet coefficient $V$ for doped and un-doped samples

\begin{tabular}{|c|c|c|}
\hline \multicolumn{2}{|c|}{ Sample } & \multirow{2}{*}{$\begin{array}{c}\text { Verdet } \\
\text { coefficient }\end{array}$} \\
\hline Material & State & \\
\hline \multirow{2}{*}{$\mathrm{Bi}_{12} \mathrm{SiO}_{20}$} & Undoped & 7.826 \\
\hline & Eu-doped & 3.454 \\
\hline \multirow{2}{*}{$\mathrm{LiNbO}_{3}$} & Undoped & 9.292 \\
\hline & Eu-doped & 4.921 \\
\hline \multirow{2}{*}{$\mathrm{Sr}_{x} \mathrm{Ba}(1-x) \mathrm{Nb}_{2} \mathrm{O}_{6}$} & Undoped & 9.824 \\
\hline & Eu-doped & 5.501 \\
\hline
\end{tabular}

\subsection{Lattice compatibility theory LCT fundaments and analysis}

From precedent analysis, it was obvious that stability of $\mathrm{Eu}^{3+}$ ions within host matrix does not occur in the same way inside the three studied as-grown lattice structures. The Lattice Compatibility Theory [18-20] tries to give a plausible understanding of this disparity starting from intrinsic doping-element lattice properties in comparison to those of the host. In the studied materials, changes in Urbach energy and Faraday effect have been associated to a Eu-doping induced disorder in host matrices against a relative unaltered stability. In this context, fundamental geometrical observations concerning the structure of $\mathrm{LiNbO}_{3} \mathrm{Sr}_{x} \mathrm{Ba}_{(1-x), x=0.5}, \mathrm{Nb}_{2} \mathrm{O}_{6}$, and $\mathrm{Bi}_{12} \mathrm{SiO}_{20}$ along with that of intrinsic $\mathrm{EuFe}_{4} \mathrm{Sb}_{12}$ (Figure 4). 


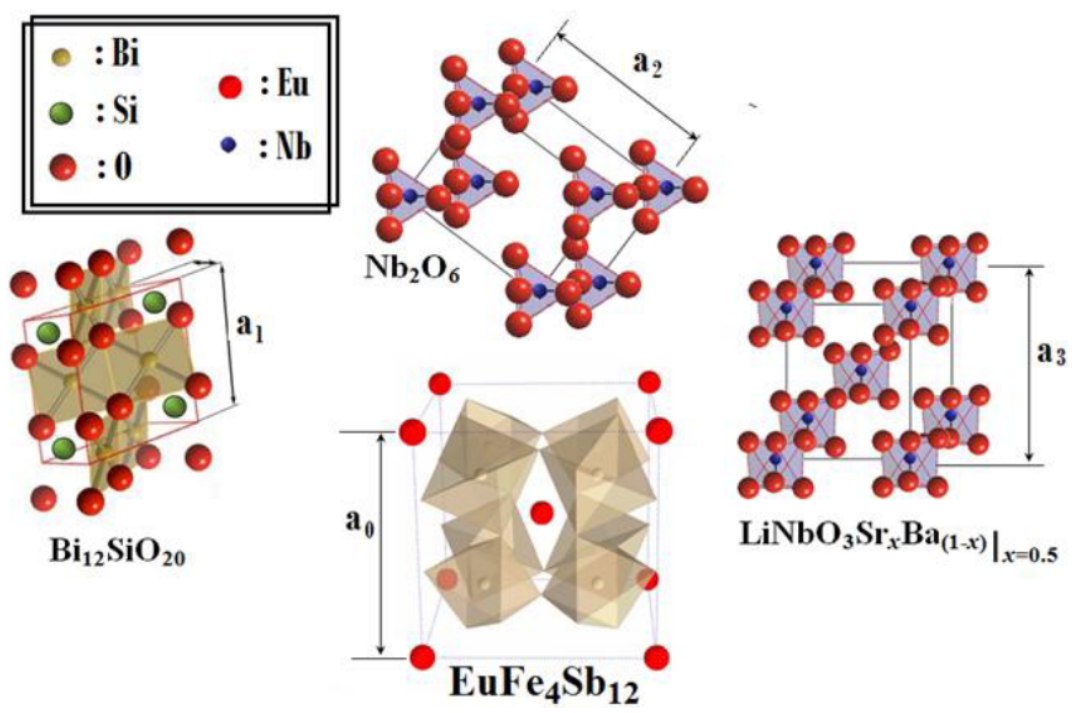

Figure 4. Studied compounds lattices structure.

As a first step, main lattice constants of Europium intrinsic lattice have been compared to those of $\mathrm{LiNbO}_{3} \mathrm{Sr}_{x} \mathrm{Ba}_{(1-x), x}, \mathrm{Nb}_{2} \mathrm{O}_{6}$, and $\mathrm{Bi}_{12} \mathrm{SiO}_{20}$. In this context, fundamental geometrical observations concerning the structure of host lattices (mainly the parameters $\mathrm{a}_{0}, \mathrm{a}_{1}, \mathrm{a}_{2}$, and $\mathrm{a}_{3}$ (in Figure 4)) revealed an obvious compatibility with the cubic main metric and angular parameters of Europium intrinsic lattice (Figure 4). This compatibility has been recorded at a higher stage for $\mathrm{Bi}_{12} \mathrm{SiO}_{20}$ samples. This feature is widely confirmed by Faraday effect and Urbach tailing analyses (Subsection 3.1). Finally, a possible explanation for the paradox of disparity of incorporation behaviours of doping agent is formulated as follows:

"The stability of doping agents inside host structures is favorized trough geometrical compatibility, expressed in terms of matching patterns between doping agent intrinsic lattice and those of the host”. 
Indeed it is the matter of a necessary but not sufficient condition. There is much to do for a strong validation of this theory. Nevertheless, for such compounds many elements of this theory are already in good agreement with results recorded by Jiao et al. [21], Soo and Jae [22], Alaparthi et al. [23], and Zhu et al. [24]. In fact, Jiao et al. [21] evoked self-reduction of $\mathrm{Eu}^{3+}$ to $\mathrm{Eu}^{2+}$ in similar systems to the actual study. In the particular case of $\mathrm{Bi}_{12} \mathrm{SiO}_{20}$, and due to this such self- reduction, it can be presumed that bismuth ion are reduced by the neighbouring $\mathrm{Eu}^{2+}$ which leads to the incorporation of formation of Europium aggregates within the altered $\mathrm{Bi}_{12} \mathrm{SiO}_{20}$ matrix. In a similar context, Soo and Jae [22] recorded ${ }^{5} \mathrm{D}_{0} \rightarrow{ }^{7} \mathrm{~F}_{J=1,2,3,4}$ transitions in trivalent europium ions pure orthorhombic $\left(\mathrm{Eu}^{2+}\right)$ doped $\mathrm{BaGd}_{2} \mathrm{Ti}_{4} \mathrm{O}_{13}$ (BGT) phosphors. Alaparthi et al. also claimed a high incorporation rate inside $\mathrm{Eu}^{3+}$ doped $\mathrm{La}_{2} \mathrm{Zr}_{2} \mathrm{O}_{7}$ and similar $\mathrm{A}_{2} \mathrm{~B}_{2} \mathrm{O}_{7}$ host cubic fluorite lattices. These results [21-25], give a strong supply to the concept of $\mathrm{Eu}^{3+}$ incorporation which is detailed in this study. They are in good agreement with those related to Europium element effect patterns during crystal growth, which were recorded by Thomas et al. [26], Louis et al. [27], Li et al. [28], Khlissa et al. [29], Mrázek et al. [30], Masubuchi et al. [31], Hernández et al. [32], Lee et al. [33], and Freyria et al. [34].

\section{Conclusion}

The present study tries to give new arguments and fundaments to the Lattice Compatibility Theory (LCT) through energy conversion-related doped crystal patterns. Main investigations have been carried out on comparative studies of the behaviour of ternary and quaternary materials like lithium liobate $\left(\mathrm{LiNbO}_{3}\right)$ strontium-barium niobate $\left(\mathrm{Sr}_{x} \mathrm{Ba}_{(1-x)} \mathrm{Nb}_{2} \mathrm{O}_{6}\right)$, sillenite single crystals $\left(\mathrm{Bi}_{12} \mathrm{SiO}_{20}\right)$ and $\left(\mathrm{Bi}_{12} \mathrm{GeO}_{20}\right)$ as-grown crystals under rare earth elements doping. Urbach tailing and Faraday effect 
along with lattice constants alterations have been compared and discussed. Recoded results were found to plea in favor of this theory, nevertheless, some experimental works on, i.e., luminescence properties, crystallization mechanism, energy storage capacity, and thermal expansion performance are needed in order to confirm exactness and validity extent.

\section{Acknowledgement}

The authors thank the Department of Agriculture, Forest, Nature and Energy (DAFNE), University of Tuscia for financially supporting this research. The second author Pr. Dr. Ing. K. Boubaker, who is an Invited Professor in the Dafne, Viterbo, Italy, is grateful to all the help he received during his mission in Tuscia University, namely from the colleagues Danilo Monarca, Andrea Colantoni, Massimo Di Franchi and the related searchers group. Particular gratefulness is expressed here, from the corresponding author, Pr. Dr. Ing. Karem Boubaker, and his doctoral fellow, Ayşe Yumak, to H. E. Ömer Gücük, the Turkish Ambassador in Tunisia, H. E. Raimondo de Cardona, the Italian Ambassador in Tunisia, along with his colleagues, Mr. Andrea Della Nebbia and Capitano di Vascello Danilo Murciano, for assistance, hints and support.

\section{References}

[1] A. Duk, J. Schwarzkopf, A. Kwasniewski, M. Schmidbauer and R. Fornari, Materials Research Bulletin 47(8) (2012), 2056-2061.

[2] J. Zhang Zhou, Y. Liu and G. Wang, Materials Research Bulletin 47(4) (2012), 1104-1106.

[3] N. F. Mott, Nobel Prize Lecture, 1977.

[4] W. W. Li, J. J. Zhu, J. D. Wu, J. Sun, M. Zhu, Z. G. Hu and J. H. Chu, ACS Appl. Mater. Interfaces 2 (2010), 2325-2332.

[5] H. Kimura, T. Fukumura, M. Kawasaki, K. Inaba, T. Hasegawa and H. Koinuma, Appl. Phys. Lett. 80 (2002), 94-96. 
[6] S. J. Liu, C. Y. Liu, J. Y. Juang and H. W. Fang, J. Appl. Phys. 105 (2009), 013928.

[7] R. K. Verma, G. Kaur, A. Rai and S. B. Rai, Materials Research Bulletin 47 (2012), 3726-3731.

[8] W. Huang, C. Lu, C. Jiang, J. Jin, M. Ding, Y. Ni and Z. Xu, Materials Research Bulletin 47 (2012), 3726-3731.

[9] X. Qiao, X. Fan, Y. Pan, A. Lotnyk and L. Kienle, Materials Research Bulletin 47 (2012), 29-34.

[10] B. Liu, C. W. Cheng, R. Chen, Z. X. Shen, H. J. Fan and H. D. Sun, J. Phys. Chem. C 114 (2010), 3407-3410.

[11] H. Tran, T. Mehta, M. Zeller and R. H. Jarman, Materials Research Bulletin 48 (2013), 2450-2456.

[12] P. A. Lessing, Ceramic Bulletin 68 (1989), 1002-1006.

[13] E. Niwa, C. Uematsu and T. Hashimoto, Materials Research Bulletin 48 (2013), 1-6.

[14] R. H. Jarman, J. Bafia, T. Gebreslasse, B. J. Ingram and J. D. Carter, Materials Research Bulletin 48 (2013), 3916-3918.

[15] Y. Hasegawa, M. Yamamuro, Y. Wada, N. Kanehisa, Y. Kai and S. Yanagida, J. Phys. Chem. A 107 (2003), 1697-1702.

[16] P. Marwoto, S Sugianto and E Wibowo, J. of Theoret. and Applied Physics 6 (2012), 17-22.

[17] C. D. Hodgman, Handbook of Chemistry and Physics 35th Ed., Vol. 2, (Chemical Rubber Publishing Co., 1953), 2737.

[18] P. Petkova and K. Boubaker, J. of Alloys and Compounds 546(5) (2013), 1769-1777.

[19] K. Boubaker, ISRN Nanomaterials 2012 (2012), 4-8.

[20] K. Boubaker, J. of Ceramics 2013 (2013), 6-9.

[21] Q. Jiao, J. Qiu, D. Zhou and X. Xu, Materials Research Bulletin 51 (2014), 315-319.

[22] H. L. Soo and S. Y. Jae, Materials Research Bulletin 50 (2014), 354-358.

[23] S. B. Alaparthi, L. Lu, Y. Tian and Y. Mao, Research Bulletin 49 (2014), 114-118.

[24] G. Zhu, Z. Ci, C. Ma, Y. Shi, Y. Wang and Mao, Materials Research Bulletin 48 (2013), 1995-1998.

[25] K. Chakraborty, A. Bisoi, B. N. Ganguly, V. Grover, F. N. Sayed and A. K. Tyagi, Materials Research Bulletin 47 (2012), 3660-3664.

[26] T. Thomas, X. Guo, M. Chandrashekhar, C. B. Poitras, W. Shaff, M. Dreibelbis, J. Reiherzer, K. Li, Francis J. DiSalvo, M. Lipson and M. G. Spencer, Journal of Crystal Growth 311 (2009), 4402-4407.

[27] C. Louis, K. Lebbou, M. A. Flores-Gonzalez, R. Bazzi, B. Hautefeuille, B. Mercier, S. Roux, P. Perriat, C. Olagnon and O. Tillement, Journal of Crystal Growth 265 (2004), 459-465. 
[28] X. Li, Z. Yang, L. Guan, C. Liu and P. Li, Journal of Crystal Growth 310 (2008), 3117-3120.

[29] F. Khlissa, M. Férid, M. C. Pujol, X. Mateos, J. J. Carvajal, F. Díaz and M. Aguiló, Journal of Crystal Growth 311 (2009), 4360-4364.

[30] J. Mrázek, M. Surýnek, S. Bakardjieva, J. Buršík and I. Kašík, Journal of Crystal Growth 391 (2014), 25-32.

[31] Y. Masubuchi, T. Hata, T. Motohashi and S. Kikkawa, Journal of Solid State Chemistry 184 (2011), 2533-2537.

[32] W. Y. Hernández, O. H. Laguna, M. A. Centeno and J. A. Odriozola, Journal of Solid State Chemistry 184 (2011), 3014-3020.

[33] D. Lee, J. Seo, L. de los Santos Valladares, O. Avalos Quispe and C. H. W. Barnes, Journal of Solid State Chemistry 228 (2015), 141-145.

[34] F. S. Freyria, G. Barrera, P. Tiberto, E. Belluso, D. Levy, G. Saracco, P. Allia, E. Garrone and B. Bonelli, Journal of Solid State Chemistry 201 (2013), 302-311. 